\title{
Adsorption of Three Commercial Dyes onto Chitosan Beads Using Spectrophotometric Determination and a Multivariate Calibration Method
}

\author{
Manuela Mincea $^{1 * \#}$, Viorica Patrulea $^{1 \#}$, Ana Negrulescu ${ }^{1}$, Robert Szabo $^{2}$, Vasile Ostafe $^{1 \dagger}$ \\ ${ }^{1}$ Advanced Environmental Research Laboratories, West University of Timisoara, Timisoara, Romania \\ ${ }^{2}$ Faculty of Mathematics and Computer Science, West University of Timisoara, Timisoara, Romania \\ Email: ${ }^{\dagger}$ vostafe@cbg.uvt.ro
}

Received December 16, 2012; revised January 21, 2013; accepted January 30, 2013

Copyright (C) 2013 Manuela Mincea et al. This is an open access article distributed under the Creative Commons Attribution License, which permits unrestricted use, distribution, and reproduction in any medium, provided the original work is properly cited.

\begin{abstract}
A simple and rapid analytical method for the simultaneous quantification of three commercial azo dyes-Tartrazine (TAR), Congo Red (CR), and Amido Black (AB) in water is presented. The simultaneous assessment of the individual concentration of an organic dye in mixtures using a spectrophotometric method is a difficult procedure in analytical chemistry, due to spectral overlapping. This drawback can be overcome if a multivariate calibration method such as Partial Least Squares Regression (PLSR) is used. This study presents a calibration model based on absorption spectra in the $300-650 \mathrm{~nm}$ range for a set of 20 different mixtures of dyes, followed by the prediction of the concentrations of dyes in 6 validation mixtures, randomly selected, using the PLSR method. Estimated limits of detection (LOD) were $0.106,0.047$ and $0.079 \mathrm{mg} / \mathrm{L}$ for TAR, CR, and $\mathrm{AB}$, respectively, and limits of quantification (LOQ) were $0.355,0.157$ and $0.265 \mathrm{mg} / \mathrm{L}$ for TAR, CR, and $\mathrm{AB}$, respectively. Quantitative determination of the three azo dyes was performed following optimized adsorption experiments onto chitosan beads of mixtures of TAR, CR and AB. Adsorption isotherm and kinetic studies were carried out, proving that the proposed PLSR method is rapid, accurate and reliable.
\end{abstract}

Keywords: Univariate Calibration; Multivariate Calibration; Spectral Overlap; Partial Least Squares Regression; Commercial Dyes; Adsorption

\section{Introduction}

During the past decades, many methods for the assay and removal of chemical compounds from wastewaters have been developed. This is an important consequence of the growing awareness raised by the effect of water pollution on the environment [1].

One major contributor to wastewater pollution is dyes. Both natural and synthetic dyes are extensively used in many human activities, such as food and beverages industry, textile, leather, cosmetic and drugs industries and many more $[2,3]$. The present study focuses on three industrially used dyes, Tartrazine (TAR) (Figure 1(a)), which is applied in coloring soft drinks, foods, drugs and cosmetics [3], Congo Red (CR) (Figure 1(c)), used in paper, plastic, textile and dyes industries $[4,5]$, and Amido Black (AB) (Figure 1(b)), which can be con-

\footnotetext{
"Manuela Mincea is temporally affiliated to "Alexandru Ioan Cuza" University, Iasi, Romania.

${ }^{\#}$ Co-first authors.

${ }^{\dagger}$ Corresponding author.
}

tained by inks, paints and leather colorings, due to its applicability on different natural and synthetic fibers, such as cotton, silk, polyesters, rayon and so on [6]. In higher amount, besides the intense colors of wastewaters resulting from the previously mentioned industries, these dyes are toxic $[2,7,8]$. Previous studies emphasized that a concentration of dye as low as $1 \mathrm{mg} / \mathrm{L}$, determines the visible coloration of water [2] and concentrations from $10-25 \mathrm{mg} / \mathrm{L}$ have serious effects on the health and life of zooplankton and water ecosystem fish populations [9]. When dyes are discharged in rivers they are diluted, and in wastewaters they have concentration ranging within the level of $\mu \mathrm{g} / \mathrm{L}[10]$. Due to the fact that dyes are stable to oxidizing agents, light and heat, their removal from wastewaters represents a great challenge. Moreover, most dyes, especially synthetic ones are biologically non-degradable [7].

The spectrophotometric determination has been widely used for dyes, especially when the purpose was to assess singular dye concentrations. Nevertheless, there is more 
<smiles>CS(=O)(=O)c1ccc(N=Nc2c(C(N)=O)nn(-c3ccc(S(N)(=O)=O)cc3)c2O)cc1</smiles>

(a)<smiles>N#[N+]Oc1cc2cc(S(=O)(=O)[O-])c(N=Nc3ccc([N+](=O)[O-])cc3)c(N)c2c(O)c1N=Nc1ccccc1</smiles>

(b)<smiles>Nc1c(N=Nc2ccc([N+](=O)[O-])cc2)c(S(=O)(=O)[O-])cc2cc(SO)c(N=Nc3ccccc3)c(O)c12</smiles>

(c)

Figure 1. The chemical structures of industrial dyes: (a) Tartrazine; (b) Amido Black; (c) Congo Red.

complexity when dealing with a mixture of dyes, as they might have spectral interferences, resulting from the overlapping of absorption bands [11].

In search for more accurate and higher resolution detections considering the presence of overlapped spectra, numerous assay methods have been used, from the classical spectrophotometric method [12], and derivative spectrophotometry $[13,14]$, to chemometric techniques such as classical least squares (CLS), principal components regression (PCR), and partial least squares regression (PLSR) [15-18]. Other equally employed methods are H-point standard addition method [19], capillary zone electrophoresis [20], polarography [21], and HPLC [3]. Chemometric techniques are usually chosen in combination with an analytical method, such as those mentioned before, due to the fact that they make possible the prediction of unknown concentration of numerous dyes in mixtures, as long as for all the substances in the mixture a unambiguous parameter/property is known.

The quantification of the mixtures of dyes can be performed spectrophotometrically, but in the situation of the spectral overlap, this method is non-discriminatory, making it impossible to determine the exact concentration of each dye in the mixture. As opposed to the univariate calibration method, the multivariate calibration method is favored for analyzing a mixture of dyes $[10,11,16]$. The classical univariate calibration method is applied with very little success to mixtures of dyes, because there is an involvement of all dyes in the absorption signals, at any given wavelength. In this work, we have used the multivariate calibration, represented by PLSR calibration me- thod, in order to predict as accurate as possible the concentrations of TAR, CR and AB in their mixtures. Some characteristic of these three azo dyes are presented in Table 1 and their chemical structures in Figure 1. Parameters which describe the quality of the proposed method such as linear range, limit of detection (LOD) and limit of quantification (LOQ) were calculated.

\subsection{Theoretical Background for the Multivariate Calibration Method}

The following notations were chosen, the matrices were capital letters (matrices $A, C, K$ and $E$ ), the transposed matrices were represented with superscript $t\left(A_{t}\right)$, vectors and scalars were symbolized with small letters $(v, c)$ and the Euclidian norm for the vector was represented as \|II\|.

The Lambert Beer model for $m$ calibration standards containing $l$ dyes with spectra of $n$ measured values of absorbance can be presented in matrix notation as [15]:

$$
A=C \cdot K+E
$$

Or in matrix form,

$$
\begin{aligned}
& {\left[\begin{array}{cccc}
A_{11} & A_{12} & \cdots & A_{1 n} \\
A_{21} & A_{22} & \cdots & A_{2 n} \\
\vdots & \vdots & \ddots & \vdots \\
A_{m 1} & A_{m 2} & \cdots & A_{m n}
\end{array}\right] } \\
= & {\left[\begin{array}{cccc}
C_{11} & C_{12} & \cdots & C_{1 l} \\
C_{21} & C_{22} & \cdots & C_{2 l} \\
\vdots & \vdots & \ddots & \vdots \\
C_{m 1} & C_{m 2} & \cdots & C_{m l}
\end{array}\right] \times\left[\begin{array}{cccc}
K_{11} & K_{12} & \cdots & K_{1 n} \\
K_{21} & K_{22} & \cdots & K_{2 n} \\
\vdots & \vdots & \ddots & \vdots \\
K_{l 1} & K_{l 2} & \cdots & K_{l n}
\end{array}\right] } \\
& +\left[\begin{array}{cccc}
E_{11} & E_{12} & \cdots & E_{1 n} \\
E_{21} & E_{22} & \cdots & E_{2 n} \\
\vdots & \vdots & \ddots & \vdots \\
E_{m 1} & E_{m 2} & \cdots & E_{m n}
\end{array}\right]
\end{aligned}
$$

where $A$ is the $m \times n$ matrix containing the values of adsorption obtained from calibration spectra, $C$ is the $m \times l$ matrix comprising the concentration of dyes, $K$ is the $l \times n$ matrix formed of constants of absorption or simply the calibration matrix. $E$ is the $m \times n$ matrix of spectral errors that not fit the model of prediction. The elements of $K$ matrix are determined by measuring the

Table 1. Description of dyes selected in the present study.

\begin{tabular}{ccccc}
\hline Name & Structural formula & $\begin{array}{c}\mathrm{MW} \\
(\mathrm{g} / \mathrm{mol})\end{array}$ & $\begin{array}{c}\lambda_{\max } \\
(\mathrm{nm})\end{array}$ & Chromophore \\
\hline TAR & $\mathrm{C}_{29} \mathrm{H}_{19} \mathrm{~N}_{5} \mathrm{O}_{8} \mathrm{~S}_{2} \mathrm{Na}_{2}$ & 534.3 & 426.5 & Azo \\
$\mathrm{CR}$ & $\mathrm{C}_{32} \mathrm{H}_{22} \mathrm{~N}_{6} \mathrm{Na}_{2} \mathrm{O}_{6} \mathrm{~S}_{2}$ & 696.665 & 486.5 & Diazo \\
$\mathrm{AB}$ & $\mathrm{C}_{22} \mathrm{H}_{14} \mathrm{~N}_{6} \mathrm{Na}_{2} \mathrm{O}_{9} \mathrm{~S}_{2}$ & 616.49 & 618 & Diazo \\
\hline
\end{tabular}


absorbance of mixtures of dyes and multiplying the thusly obtained matrix with the transposed matrix of the matrix consisting of the concentrations of each dye in the mixtures; simply using the value of absorbance obtained for the mixture at any wavelength to describe solely one dye is, however, not enough because there is the need to take into account overlapping between the dyes spectra. Previous chemometric techniques have been applied in studies that, in fact, solved Equation (2) and found the suitable relation between the absorbance and concentration in order to not generate errors. Such calibration methods which have been applied in chemometric research are Classical Least Squares, Principal Component Regression, Partial Least Squares $[15,16]$, and Kalman Filter [16].

The univariate method used in the present study is based on obtaining the values of absorbance for mixtures of dyes and, by means of linear regression, using the calibration curves of each dye, to obtain a possible prediction for the concentration of an individual dye.

Multivariate calibration methods include a calibration step in which the relationship between spectra and dyes concentrations is estimated from a set of calibration samples, and a prediction step in which the results of the calibration are used to predict the randomly selected dyes concentrations in an unknown sample spectrum [15].

In PLSR, the absorptions matrix can be represented as:

$$
A=T \cdot P^{t}+E_{R}
$$

where $A$ is an $m \times n$ matrix containing the values of absorbance of $\mathrm{m}$ calibration samples obtained at $n$ wavelengths, $P$ is a $n \times h$ matrix containing the full spectrum vectors, $T$ is an $m \times h$ matrix of intensities (or scores) in the novel coordinate system described by the $h$ loading vectors, and $E_{R}$ is the $m \times n$ matrix of spectral residuals not fitted by the optimal PLSR model. The loading vectors contained in $P$ are established by an iterative algorithm, which also offers a set of orthogonal weight loading factors that form the $n \times h$ matrix $W$ [22]. The relationship between $A, P, T$ and $W$ is given in the next equation:

$$
T=R \cdot W \cdot\left(P^{t} \cdot W\right)^{-1}
$$

In PLSR, the matrix $T$ is related to concentration by an inverse regression step as can be seen in the following equation:

$$
c_{k}=T \cdot v+e_{c}
$$

where $c_{k}$ is the $m \times l$ vector of the different $k$ dyes concentrations, $v$ is the $h \times l$ vector of coefficients connecting the scores to the concentrations and $e_{c}$ assembles the corresponding concentration residuals. In the prediction step, the spectrum $r$ recorded for an unknown sample is converted into the sample score $t_{r}$ by:

$$
t_{r}=\left(W^{t} \cdot P\right)^{-1} \cdot W^{\mathrm{T}} \cdot r
$$

from which the concentration can be calculated using the equation bellow:

$$
c_{k, u n}=t_{r}^{t} \cdot v
$$

where $v$ is the vector of regression coefficient from Equation (5).

\subsection{Adsorption Experiments}

A primary contemporary concern regarding wastewaters is the removal of the various pollutants. Many methods have been employed in decontaminating wastewaters, out of which one of the most efficient is adsorption. Previous studies for the adsorption of AB [23], CR [24], and TAR [25] onto chitosan have been reported, but to our knowledge, this is the first study regarding the adsorption of mixtures of these three dyes.

The adsorption studies were optimized regarding the $\mathrm{pH}$ of the aqueous solutions, the size of chitosan beads and the mass of adsorbent. Isotherm studies were performed by varying the concentrations of the dyes in mixtures, prior to undergoing adsorption. The results from the isotherms studies were fitted to four widely used isotherm models Langmuir, Freundlich, Temkin and Elovich models, in order to describe the removal mechanism of $\mathrm{TAR}, \mathrm{CR}$ and $\mathrm{AB}$ from the aqueous solutions onto chitosan beads.

The primary parameter to describe the adsorption process is the adsorption capacity of adsorbent material, $q_{e}(\mathrm{mg} / \mathrm{g})$ which was determined with the relation:

$$
q_{e}=\frac{\left(C_{0}-C_{e}\right) V}{W}
$$

where $C_{0}$ is the initial concentration of the dye $(\mathrm{mg} / \mathrm{L})$ at the beginning of the adsorptions experiment, $C_{e}$ is the final concentration (equilibrium, after two hours in the present study) of the dye $(\mathrm{mg} / \mathrm{L}), V$ is the volume of dye solution $(10 \mathrm{~mL})$ and $W$ is the weight of chitosan beads $(0.4 \mathrm{~g})$ used.

The Langmuir adsorption isotherm model describes monolayer adsorption (the adsorbed layer is one molecule thick) [26]. Adsorption can only take place at a limited number of identical sites and steric effect does not occur with neighboring sites [27] Uniform adsorption mechanisms are those described by the Langmuir isotherm model [28]. Due to the fact that for the quantification of the isotherm data only linear forms of the isotherm equations are used in this study, the linear Langmuir isotherm equation is presented below (Equation (9)).

$$
\frac{C_{e}}{q_{e}}=\frac{C_{e}}{Q_{m}}+\frac{1}{Q_{m} b}
$$


where $C_{e}$ is the final or equilibrium concentration of dye $(\mathrm{mg} / \mathrm{L}), q_{e}$ is the amount of dye adsorbed on adsorbent mass unit ( $\mathrm{mg} / \mathrm{g}), Q_{m}$ is the maximum adsorption capacity of dyes $(\mathrm{mg} / \mathrm{g})$, and $b$ is the Langmuir adsorption equilibrium constant $(\mathrm{L} / \mathrm{mg})$. This linear form is used to plot $C_{e} / q_{e}$ as a function of $C_{e}$ in order to determine the values of the constants in the equation.

Freundlich isotherm model [29] describes a multilayer adsorption mechanism on heterogeneous surface [30] not restricted to the formation of the monolayer, where there is the possibility for the reversibility of adsorption. The linear Freundlich equation is given by Equation (10):

$$
\ln q_{e}=\frac{1}{n} \ln C_{e}+\ln K_{F}
$$

where $C_{e}$ is the equilibrium concentration of dye $(\mathrm{mg} / \mathrm{L})$, $q_{e}$ is the amount of dye adsorbed on adsorbent mass unit $(\mathrm{mg} / \mathrm{g}), K_{F}$ is the maximum adsorption capacity of dye $(\mathrm{mg} / \mathrm{g})$, and $n$ is a constant which describes the adsorption intensity.

Temkin isotherm model [31] characterizes a mechanism of adsorption for which a linear reduction of the heat of adsorption occurs for all the molecules in the layer, due to the interactions between the sorbent and the sorbate, diminishing with the filling of adsorption sites. The linear form of the Temkin equation is given by Equation (11):

$$
q_{e}=\frac{R T}{\Delta Q} \ln K_{0}+\frac{R T}{\Delta Q} \ln C_{e}
$$

where $C_{e}$ is the equilibrium concentration of dye $(\mathrm{mg} / \mathrm{L})$, $q_{e}$ is the amount of dye adsorbed on adsorbent mass unit $(\mathrm{mg} / \mathrm{g}), K_{0}(\mathrm{~L} / \mathrm{g})$ is the equilibrium binding constant, characterizing the maximum binding energy, and constant $R T / \Delta Q$ is connected to the heat of adsorption. Its value, or rather, its sign is important as it can predict whether the adsorption process is exothermic or endothermic. In order to determine values of the constants a plot of $q_{e}$ versus $\ln A_{e}$ was done.

Elovich isotherm model [32] predicts a multilayer adsorption mechanism on highly heterogeneous sorbents [33] for which the adsorption sites multiply exponentially with the filling of adsorption sites. The Elovich model is also the most specific for chemisorption mechanisms of adsorption [34]. The linear Elovich equation is expressed by Equation (12):

$$
\ln \frac{q_{e}}{C_{e}}=\ln K_{E} Q_{m}-\frac{q_{e}}{Q_{m}}
$$

where $C_{e}$ is the equilibrium concentration of dye $(\mathrm{mg} / \mathrm{L})$, $q_{e}$ is the amount of dye adsorbed on adsorbent mass unit $(\mathrm{mg} / \mathrm{g}), K_{E}$ is the Elovich equilibrium constant $(\mathrm{L} / \mathrm{mg})$ and $Q_{m}$ is the Elovich maximum adsorption capacity $(\mathrm{mg} / \mathrm{g})$. In order to obtain constant values a plot is done $\ln \left(q_{e} / C_{e}\right)$ versus $q_{e}$.

\subsection{Kinetic Studies}

The mechanism of adsorption was investigated by the pseudo-first and pseudo-second kinetic models. The pseudo-first kinetic model, given by Equation (13), basically describes an adsorption process for which the adsorption of the sorbate onto the sorbent takes place predominantly at the beginning of the adsorption process [35] whereas the pseudo-second order kinetic models, given by Equation (14), illustrates the adsorption process that takes place the entire time when the sorbate is in contact with the sorbent [36] usually characteristic to multilayer adsorption models.

$$
\begin{aligned}
\log \left(q_{e}-q_{t}\right) & =\log q_{e}-\frac{k_{1}}{2.303} t \\
\frac{t}{q_{t}} & =\frac{1}{k_{2} q_{e}^{2}}+\frac{1}{q_{e}} t
\end{aligned}
$$

where $q_{e}$ is the amount of dye adsorbed $(\mathrm{mg} / \mathrm{g})$ at equilibrium, $q_{t}$ is the amount of dye adsorbed on adsorbent mass unit (mg/g) at time $t$ and $k_{1}$ and $k_{2}$ are rate constant of the first $(1 / \mathrm{min})$ and second-order adsorption $(\mathrm{g} /(\mathrm{mg} \cdot \mathrm{min}))$, respectively. In order to determine the value of $k_{2}$, a plot of $t / q_{t}$ as function of $t$ was done. The two types of kinetics models, pseudo-first and pseudo-second kinetic models were fitted to the experimentally obtained results.

\section{Experimental}

\subsection{Instrumentation and Software}

The absorbance measurements were obtained using a double beam spectrophotometer (T90+ UV/VIS Spectrometer-PG Instruments Ltd.), using $1 \mathrm{~cm}$ quartz cells. The UV-VIS spectra were recorded over the wavelength range of $300-650 \mathrm{~nm}$ and digitized values of absorbance were sampled at $5.0 \mathrm{~nm}$ intervals and then transferred to a computer for subsequent analysis.

The data analysis was done using MathCAD 14 Professional, SPSS Statistics 17.0 and Origin 7.0.

The $\mathrm{pH}$ measurements were made with a Multi $340 \mathrm{i}$ pH-meter. A thermostated shaker (Vibramax 100 Heidolph), with a constant speed of $300 \mathrm{rpm}$ at $25^{\circ} \mathrm{C} \pm 11^{\circ} \mathrm{C}$ was used for the adsorption process.

\subsection{Chemicals and Solutions}

Chitosan with a deacetylation percentage of approximately $75 \%$ - $85 \%$ (medium molecular mass) was purchased from Sigma Aldrich Chemie GmbH (Germany). The Ultrapure water and highly pure reagents were used for all preparations of the standard and sample solutions. 
The selected dyes-Tartrazine, Congo Red, and Amido Black of analytical grade (>99.9) which were purchased from Sigma Aldrich Chemie GmbH. Standard stock solutions $(100.48 \mathrm{mg} / \mathrm{L}$ TAR, $100.8 \mathrm{mg} / \mathrm{L} \mathrm{CR}$ and 100.02 $\mathrm{mg} / \mathrm{L} \mathrm{AB}$ ) were separately prepared by dissolving 0.100 $( \pm 0.001) \mathrm{g}$ in ultrapure water. Dilute solutions for the dyes mixtures were prepared by the appropriate dilution of the stock solutions. The $\mathrm{pH}$ adjustment was done with $0.5 \mathrm{M} \mathrm{HNO}_{3}$ and $0.5 \mathrm{M} \mathrm{NaOH}$. The ionic strength of dye solutions was adjusted using pure $\mathrm{NaCl}$.

\subsection{Analytical Procedure}

Solutions of known concentrations of dyes were placed in $10 \mathrm{~mL}$ volumetric flasks and completed to the final volume with ultrapure water ( $\mathrm{pH} \mathrm{6.0)}$ ). The final concentration of these solutions varied between 1.0 and $12 \mathrm{mg} / \mathrm{L}$ for each dye.

Univariate calibration method, using the absorbance values at maximum wavelength, and PLSR method, employing the recorded absorbance values between 300 and $650 \mathrm{~nm}$ as the dependent variables were performed.

To check the reproducibility of the proposed method, the determinations of all samples were performed in duplicate.

\subsection{Experimental Design-Preparation of Calibration and Prediction Sets}

The experimental design used for the PLSR is presented in Tables 2 and 3. Two sets of solutions were prepared, the calibration set and prediction (or validation) set. Calibration set is applied to create the model, while the validation set proves the efficiency of the proposed model for prediction. Due to the spectral overlap between dyes, a large number of calibration samples were necessary. Univariate calibration experiments (one-compound) were carried out to establish the concentration ranges for the determination in the mixture. 26 ternary synthetic mixtures (at $\mathrm{pH} 6.0$ and ionic strength of $0.10 \mathrm{M} \mathrm{NaCl}$ ) of dyes were prepared. For best calibration results, the spectral region within the range $300-650 \mathrm{~nm}$ was chosen. The number of experimental points $(\lambda)$ per spectrum is 71.

The degree of the difference between predicted concentrations and actual concentrations is estimated for all calibration samples in the set using prediction error sum of squares (PRESS):

$$
\text { PRESS }=\sum_{i=1}^{n}\left(C_{i, \text { pred }}-C_{i, \text { act }}\right)^{2}
$$

The general efficiency of PLSR for prediction of dyes concentrations in the validation set can be obtained by calculating REP (relative error of prediction) values for each analyte as follows [37]:
Table 2. Composition of calibration set used in the PLSR method for simultaneous determination of dyes.

\begin{tabular}{|c|c|c|c|}
\hline \multicolumn{4}{|c|}{ Calibration set } \\
\hline No. & TAR (mL) & $\mathrm{CR}(\mathrm{mL})$ & $\mathrm{AB}(\mathrm{mL})$ \\
\hline 1 & 8 & 1 & 1 \\
\hline 2 & 1 & 1 & 8 \\
\hline 3 & 1 & 8 & 1 \\
\hline 4 & 6 & 2 & 2 \\
\hline 5 & 2 & 2 & 6 \\
\hline 6 & 2 & 6 & 2 \\
\hline 7 & 4 & 3 & 3 \\
\hline 8 & 3 & 3 & 4 \\
\hline 9 & 3 & 4 & 3 \\
\hline 10 & 4 & 2 & 4 \\
\hline 11 & 4 & 4 & 2 \\
\hline 12 & 2 & 4 & 4 \\
\hline 13 & 3 & 5 & 2 \\
\hline 14 & 3 & 2 & 5 \\
\hline 15 & 5 & 3 & 2 \\
\hline 16 & 2 & 5 & 3 \\
\hline 17 & 2 & 3 & 5 \\
\hline 18 & 1 & 4.5 & 4.5 \\
\hline 19 & 4.5 & 4.5 & 1 \\
\hline 20 & 4.5 & 1 & 4.5 \\
\hline
\end{tabular}

Table 3. Composition of prediction set used in the PLSR method for simultaneous determination of dyes.

\begin{tabular}{cccc}
\hline \multicolumn{4}{c}{ Validation set $^{\mathrm{a}}$} \\
\hline No. & TAR $(\mathrm{mL})$ & $\mathrm{CR}(\mathrm{mL})$ & $\mathrm{AB}(\mathrm{mL})$ \\
\hline 1 & 7 & 1.5 & 1.5 \\
2 & 5.5 & 3.5 & 1 \\
3 & 2.5 & 1 & 6.5 \\
4 & 2 & 5.5 & 2.5 \\
5 & 2 & 3.5 & 3.5 \\
6 & 3.5 & 1 & 5.5 \\
\hline
\end{tabular}

${ }^{\mathrm{a}}$ Randomly constructed.

$$
\operatorname{REP} \%=100 \cdot\left(\frac{\sum_{i=n}^{n}\left(C_{i, \text { pred }}-C_{i, \text { act }}\right)^{2}}{\sum_{i=1}^{n}\left(C_{i, \text { act }}\right)^{2}}\right)^{\frac{1}{2}}
$$

where $n$ is the number of samples in the validation set, 6 in the present study. 
The root mean squares difference (RMSD) is an indicator of the average error of each analyte in the assessment. RMSD can be calculated for each dye in prediction samples using the following equation [38]:

$$
\mathrm{RSMD}=\sqrt{\frac{\sum_{i=1}^{n}\left(C_{i, \text { pred }}-C_{i, \text { act }}\right)^{2}}{n}}
$$

As a measure of variability of the difference between the predicted and reference values for a set of validation samples the standard error of calibration or prediction, $\operatorname{SEC}(P)$, was used $[39,40]$ :

$$
\operatorname{SEC}(P)=\sqrt{\frac{\sum_{i=1}^{n}\left(C_{i, \text { pred }}-C_{i, \text { act }}\right)^{2}}{n-1}}
$$

\subsection{Preparation of Chitosan Beads}

The chitosan solution was prepared by dissolving approximately $1.00 \mathrm{~g}$ of chitosan powder into $30 \mathrm{~mL}$ of $2 \%$ acetic acid solution. The viscous solution was left overnight before it was dispersed drop-wise into a precipitation bath containing $500 \mathrm{~mL}$ of $0.5 \mathrm{M} \mathrm{NaOH}$, which neutralizing the acetic acid within the chitosan solution transformed the chitosan gel into spherical homogeneous gel beads. The aqueous $\mathrm{NaOH}$ solution was kept under a mild, continuous stirring. The wet chitosan gel beads were extensively rinsed with distilled water to remove any $\mathrm{NaOH}$ and sieved to $1 \mathrm{~mm}$ diameter. Prior to the adsorption experiments, the chitosan beads were kept at $4^{\circ} \mathrm{C}$.

\subsection{Adsorption Experiments}

Solutions of dyes with concentrations between $2 \mathrm{mg} / \mathrm{L}$ and $50 \mathrm{mg} / \mathrm{L}$ were obtained by diluting with ultrapure water the appropriate volume of TAR, CR and AB stock solutions. The adsorption of a mixture of these dyes was carried out in a batch process at room temperature $\left(25^{\circ} \mathrm{C}\right.$ $\pm 1{ }^{\circ} \mathrm{C}$ ), where approx. $0.4 \mathrm{~g}$ of chitosan beads were placed in $20 \mathrm{~mL}$ of dye solutions and were stirred at 300 rpm for 2 hours. Samples from the adsorption experiments mixtures were taken at zero and 2 hours time and were spectrophotometrically assayed. For the adsorption isotherm studies, various dye concentrations were tested.

\subsection{Kinetic Studies}

The batch kinetic studies were realized by adding approx. $0.4 \mathrm{~g}$ of chitosan beads in mixtures of the dyes, having the same initial concentration of each dye, $8.34 \mathrm{mg} / \mathrm{L}$ TAR, $8.34 \mathrm{mg} / \mathrm{L} \mathrm{CR}$ and $5 \mathrm{mg} / \mathrm{L} \mathrm{AB}$ and by varying the adsorption time. At various time intervals, each solution was filtered and the absorbance of the remaining quantity of the dyes was measured using the spectrophotometer.

\section{Results and Discussion}

\subsection{Chemometric Methods of Validation}

Due to the significant spectral overlap (Figure 2) that occurs between studied dyes, the conventional calibration procedures would have a limited application for quantitative determination. Thus, an accurate quantification of these dyes in the ternary system requires the use of a chemometric technique, such as the PLSR calibration.

In the case of $\mathrm{AB}$, a lower spectral overlap compared to the other two dyes can be observed. The maximum overlap was observed for TAR, which may lead to errors in the case of univariate calibration method.

The linear range of concentrations for each individual dye was established from the plot of absorbance against concentration, at the corresponding maximum wavelength. This concentration range is useful to foresee the construction of the calibration and prediction sets, concluding that all standard calibration plots were linear over the range $1-50 \mathrm{mg} / \mathrm{L}$, with correlation coefficients better than 0.9978 for all three dyes. The limit of detection (LOD) was calculated as $3 \sigma /$ slope, while the limit of quantification (LOQ) was determined as $10 \sigma /$ slope, where $\sigma$ is the standard deviation of noise. The LOD and LOQ values are presented in Table $\mathbf{4}$, as well as other linear regression parameters.

\subsection{Univariate Spectrophotometric Calibration}

For the univariate determination, the following maximum absorption wavelengths were chosen: TAR, $426.5 \mathrm{~nm}$; $\mathrm{CR}, 486.5 \mathrm{~nm}$; AB, $618 \mathrm{~nm}$. By using these wavelengths and pure standard solutions, conventional calibration curves were made, for which equations and correlation coefficients $(R)$ are presented in Figure 3. By using these calibration curves, the determination of 26 synthetic mixtures was carried out.

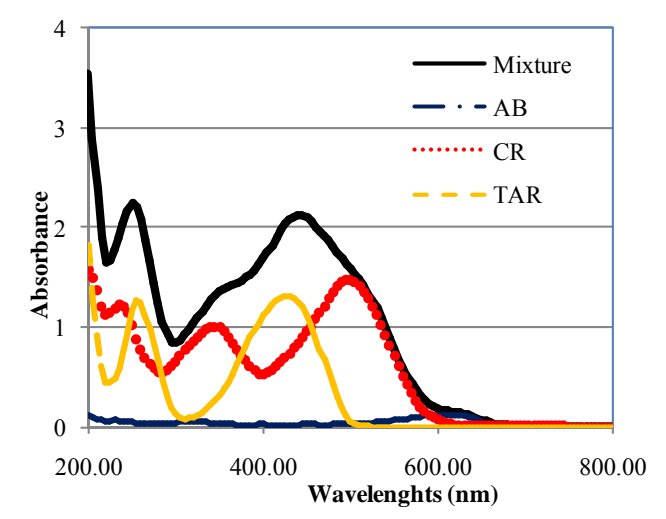

Figure 2. Absorption spectra of the single dye: Tartrazine of $50 \mathrm{mg} / \mathrm{L}$ (dashed line), Congo Red of $25 \mathrm{mg} / \mathrm{L}$ (dotted line), Amido Black of 15 mg/L (dash and dot line) and mixture spectrum is marked with continuous line. Spectra were recorded at $\mathrm{pH} 6.0$ and $0.10 \mathrm{M} \mathrm{NaCl}$. 


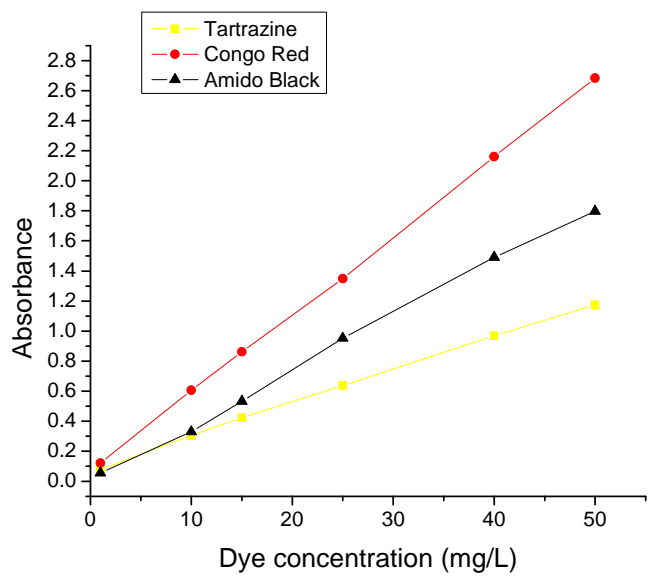

Figure 3. Analytical curves for univariate determination of synthetic dye mixtures. TAR: Ab. $=0.0222 \times$ Conc. + 0.0754; $R^{2}=0.9991 ; \lambda=426.5$ nm. CR: Ab. $=0.0521 \times$ Conc. + $0.0727 ; R^{2}=0.9998 ; \lambda=486.5$ nm. AB: Ab. $=0.0365 \times$ Conc. $+0.0018 ; R^{2}=0.9978 ; \lambda=618 \mathrm{~nm}$.

Table 4. Analytical characteristics for single-component determination of dyes at their corresponding visible $\lambda_{\max }$.

\begin{tabular}{cccccc}
\hline Dye & $\lambda_{\max }(\mathrm{nm})$ & Slope & $\begin{array}{c}\text { Linear range } \\
(\mathrm{mg} / \mathrm{L})\end{array}$ & $\begin{array}{c}\mathrm{LOD} \\
(\mathrm{mg} / \mathrm{L})^{\mathrm{a}}\end{array}$ & $\begin{array}{c}\text { LOQ } \\
(\mathrm{mg} / \mathrm{L})^{\mathrm{b}}\end{array}$ \\
\hline TAR & 426.5 & 0.0222 & $0.4-200$ & 0.106 & 0.355 \\
$\mathrm{CR}$ & 486.5 & 0.0521 & $0.2-50$ & 0.047 & 0.157 \\
$\mathrm{AB}$ & 618 & 0.0365 & $0.3-120$ & 0.079 & 0.265 \\
\hline
\end{tabular}

${ }^{\mathrm{a}}$ Limit of detection $=3 \sigma /$ slope; $\sigma=$ standard deviation of noise $(n=10)$; ${ }^{\mathrm{b}}$ Limit of quantification $=10 \sigma /$ slope; $\sigma=$ standard deviation of noise $(n=$ 10).

As expected, lower values of the standard deviation can be observed in the case of AB, explicable by its less spectral overlap with the spectra of TAR and CR. TAR has the highest values for the standard deviation (Table 5 and Figure 4(b)) presenting the maximum overlapping out of the three dyes.

\subsection{Multivariate Spectrophotometric Calibration}

The concentrations predicted by the PLSR model are similar to the real concentrations, as shown in Figure 4(a), which indicates the validity of the calibration model.

Six synthetic mixtures were analyzed using the PLSR model. It can be observed from this set of results that the dye mixtures determination is very practical (Table 6). The multivariate calibration model allows a significant reduction of the error in relation to the determination by the univariate calibration (Table 5) which demonstrates that the multivariate method is a powerful tool for difficult determinations.

The calibration parameters acquired from the multivariate validation (validation for the calibration set) are shown in Table 7. Similar spectral regions were used in
Table 5. Statistical parameters estimated during the external validation of the univariate calibration method proposed for dyes mixtures.

\begin{tabular}{cccccccccc}
\hline \multirow{2}{*}{$\mathrm{Nr}$} & \multicolumn{3}{c}{ Added $(\mathrm{mg} / \mathrm{L})$} & \multicolumn{3}{c}{ Found $(\mathrm{mg} / \mathrm{L})$} & \multicolumn{3}{c}{ Standard deviation } \\
\cline { 2 - 10 } & TAR & CR & AB & TAR & CR & AB & TAR & CR & AB \\
\hline 1 & 7 & 2.25 & 0.75 & 7.865 & 1.79 & 0.827 & 0.61 & 0.33 & 0.05 \\
2 & 5.5 & 5.25 & 0.5 & 9.754 & 4.591 & 0.567 & 3.01 & 0.47 & 0.05 \\
3 & 2.5 & 1.5 & 3.25 & 2.559 & 0.964 & 2.95 & 0.04 & 0.38 & 0.21 \\
4 & 2 & 8.25 & 1.25 & 9.664 & 7.181 & 1.252 & 5.42 & 0.76 & 0.00 \\
5 & 2 & 5.25 & 1.75 & 7.281 & 5.109 & 1.813 & 3.73 & 0.1 & 0.04 \\
6 & 3.5 & 1.5 & 2.75 & 3.818 & 1.195 & 2.238 & 0.22 & 0.22 & 0.36 \\
\hline
\end{tabular}

Table 6. Statistical parameters estimated during the external validation of the multivariate calibration method proposed for dyes mixtures.

\begin{tabular}{ccccccccccc}
\hline \multirow{2}{*}{$\mathrm{Nr}$} & \multicolumn{3}{c}{ Added (mg/L) } & \multicolumn{3}{c}{ Found (mg/L) } & \multicolumn{4}{c}{$\begin{array}{c}\text { Standard deviation } \\
(\mathrm{mg} / \mathrm{L})\end{array}$} \\
\cline { 2 - 10 } & TAR & CR & AB & TAR & CR & AB & TAR & CR & AB \\
\hline 1 & 7 & 2.25 & 0.75 & 7.160 & 2.265 & 0.832 & 0.11 & 0.01 & 0.06 \\
2 & 5.5 & 5.25 & 0.5 & 5.484 & 5.367 & 0.468 & 0.01 & 0.08 & 0.02 \\
3 & 2.5 & 1.5 & 3.25 & 2.623 & 1.527 & 2.964 & 0.09 & 0.02 & 0.20 \\
4 & 2 & 8.25 & 1.25 & 1.871 & 8.403 & 1.122 & 0.09 & 0.11 & 0.09 \\
5 & 2 & 5.25 & 1.75 & 2.095 & 6.114 & 1.786 & 0.07 & 0.61 & 0.03 \\
6 & 3.5 & 1.5 & 2.75 & 3.627 & 1.846 & 2.310 & 0.09 & 0.24 & 0.31 \\
\hline
\end{tabular}

PLSR calibration for the dyes analyzed. PRESS is a measure of how well the use of the fitted values for a subset model can predict the observed responses [39]. The best regression will have a relatively small predictive sum of squares, as is the case of the multivariate calibration for TAR and $\mathrm{AB}$ and for the univariate calibration in the case of AB. Overall smaller sum of squares are obtained for the multivariate calibration. High prediction ability of PLSR method for all dyes in calibration samples is indicated by REP\% values. The REP and SEC values should also be the lowest for best similarity between actual and predicted values and both statistical parameters have smallest values for multivariate calibration.

The results of RMSD, REP\% and SEC, obtained for prediction set (Table 7) were suitable indicating the successful application of the PLSR method for simultaneous determination of the three dyes.

\subsection{Adsorption Experiments}

The spectrophotometric method was tested for applicability in determining the concentration of TAR, CR and $\mathrm{AB}$ from aqueous solutions that were submitted beforehand to adsorption onto chitosan beads. Following the adsorption of dyes onto chitosan beads, the resulting concentration values were used to determine the adsorption 


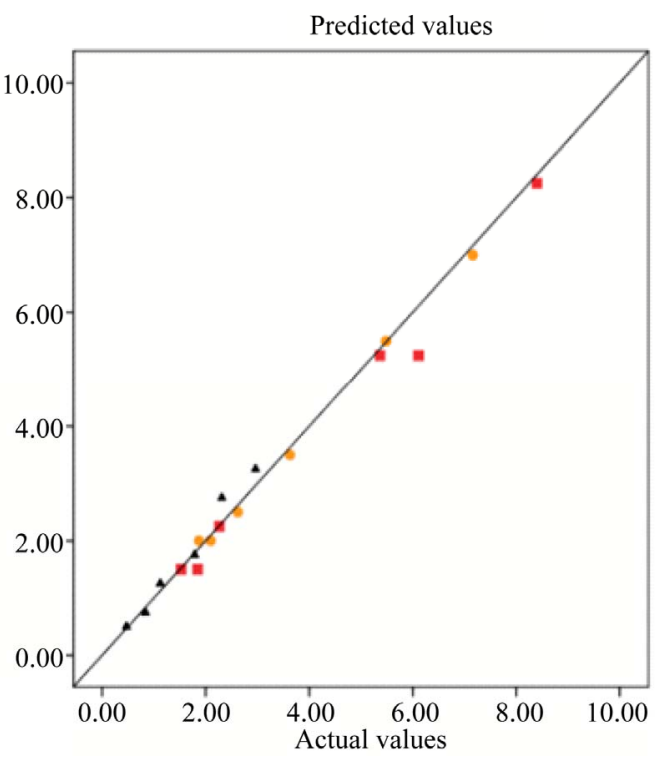

(a)

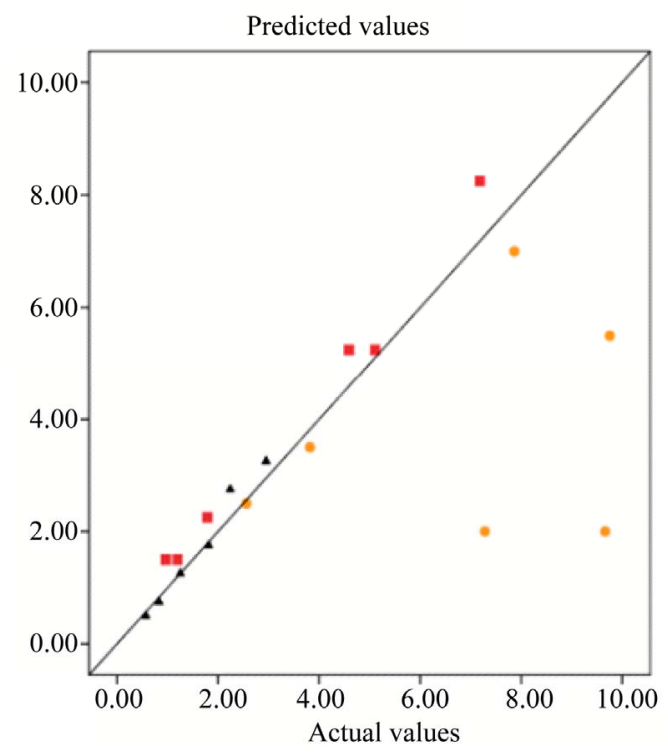

(b)

Figure 4. Real concentration versus concentration predicted by: (a) PLSR model for multivariate calibration method and (b) linear regression for univariate calibration method.

Table 7. Calibration results and statistical parameters for the univariate and multivariate methods.

\begin{tabular}{ccccccc}
\hline \multirow{2}{*}{$\begin{array}{c}\text { Calibration } \\
\text { parameter }\end{array}$} & \multicolumn{3}{c}{ Univariate calibration } & \multicolumn{3}{c}{ Multivariate calibration } \\
\cline { 2 - 7 } & TAR & CR & AB & TAR & CR & AB \\
\hline $\begin{array}{c}\text { Wavelength } \\
(\mathrm{nm})\end{array}$ & 426.5 & 486.5 & 618 & Spectral region $300-650$ \\
$\begin{array}{c}\text { PRESS } \\
\left(\mathrm{mg}^{2} / \mathrm{L}^{2}\right)\end{array}$ & 340.07 & 10.049 & 0.364 & 0.13 & 2.316 & 0.59 \\
$\mathrm{RMSD}(\mathrm{mg} / \mathrm{L})$ & 4.195 & 0.604 & 0.247 & 0.117 & 0.388 & 0.224 \\
$\mathrm{REP} \%$ & 99.917 & 12.841 & 12.472 & 2.798 & 8.253 & 11.299 \\
$\mathrm{SEC}(\mathrm{mg} / \mathrm{L})$ & 4.595 & 0.662 & 0.271 & 0.129 & 0.425 & 0.245 \\
\hline
\end{tabular}

capacity, and afterwards, both the equilibrium concentration and adsorption capacity values were fitted to four theoretical isotherm models, Langmuir, Freundlich, Temkin, and Elovich (Figures 5-7).

\subsection{Optimization of Experimental Conditions Affecting Dyes Absorption}

Many experimental conditions may affect the absorption characteristics of dyes, among these, $\mathrm{pH}$, mass of adsorbent and particle size. The influence of $\mathrm{pH}$ on dyes absorption intensity was studied over a wide $\mathrm{pH}$ range $(2-$ 12) and at constant solution ionic strength $(0.1 \mathrm{M} \mathrm{NaCl})$. The optimum $\mathrm{pH}$ for the adsorption of all three dyes was 6.0 (Figure 8), because of the high adsorption capacity obtained for TAR, CR and AB.

The variation of the adsorption capacity as a function of the mass of adsorbent is presented in Figure 9. The mass of sorbent was varied between 0.05 and $0.5 \mathrm{~g}$, while

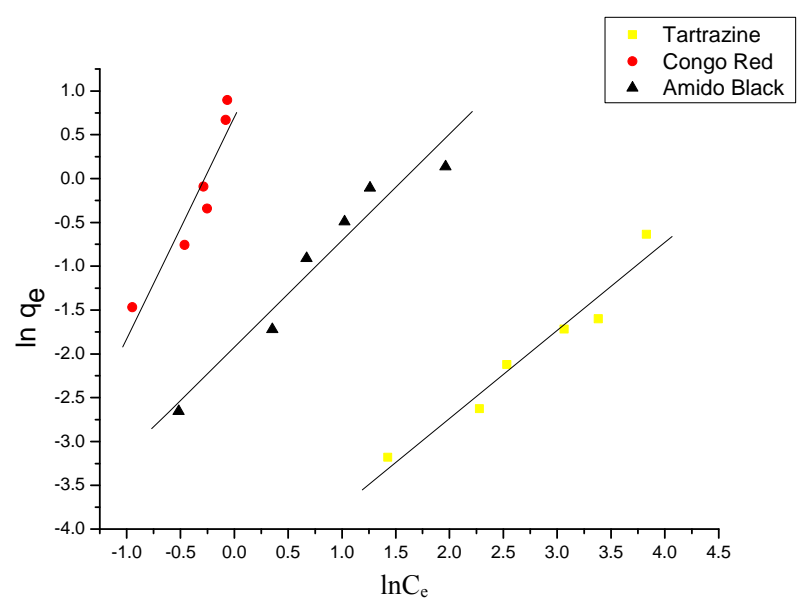

Figure 5. Adsorption isotherms of TAR, CR and AB onto chitosan beads, linearized according to Freundlich equation.

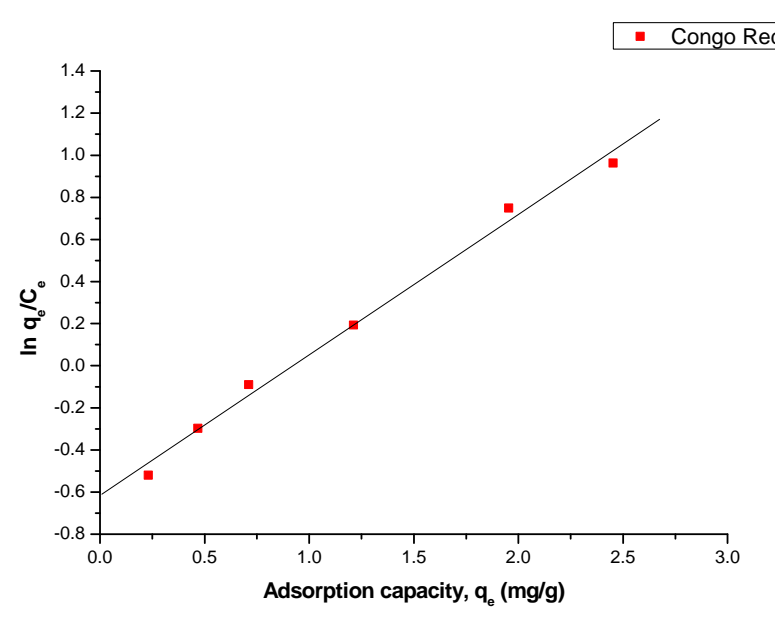

Figure 6. Adsorption isotherm for CR onto chitosan beads, linearized according to Elovich equation. 


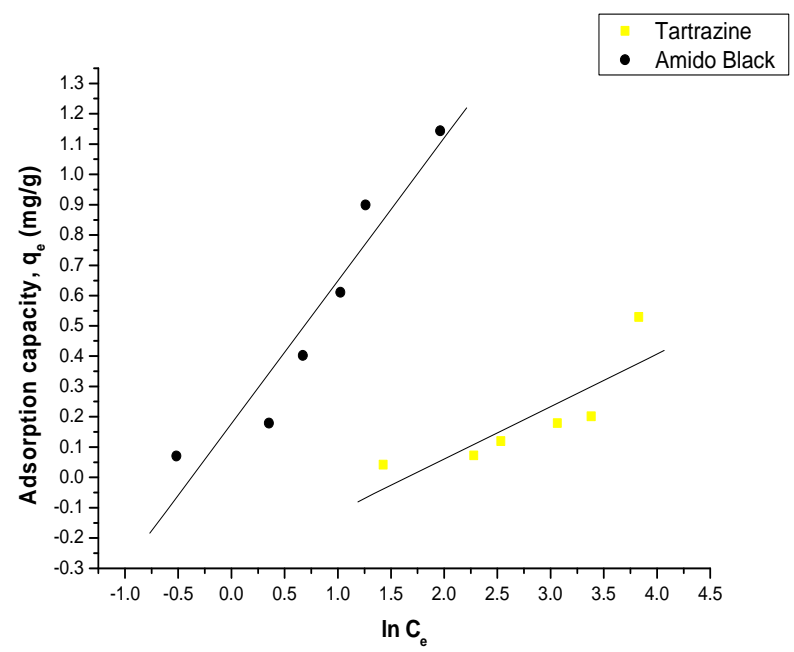

(a)

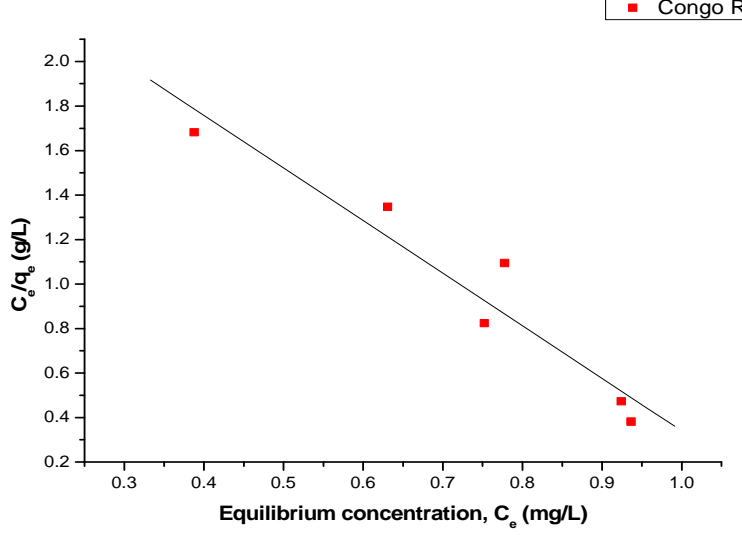

(b)

Figure 7. Adsorption isotherms of: (a) TAR, and AB onto chitosan beads, linearized according to Temkin equation; (b) CR onto chitosan beads, linearized according to Langmuir equation.

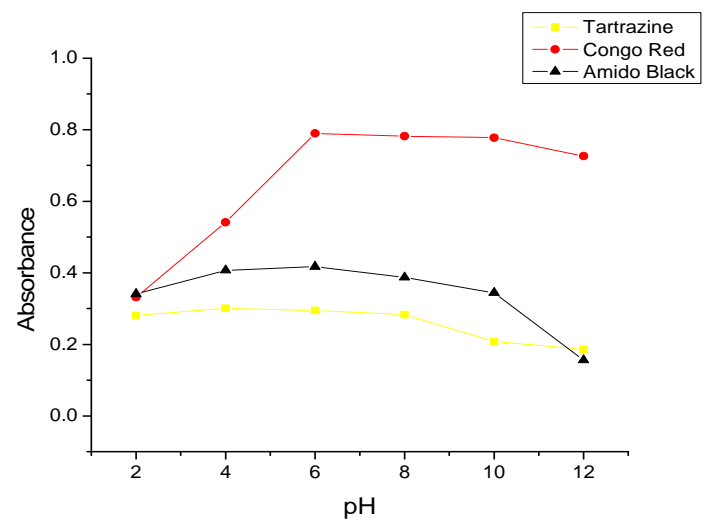

Figure 8. Influence of $\mathrm{pH}$ on the absorption of TAR (10 $\mathrm{mg} / \mathrm{L}$ and $0.10 \mathrm{M} \mathrm{NaCl}), \mathrm{CR}(15 \mathrm{mg} / \mathrm{L}$ and $0.10 \mathrm{M} \mathrm{NaCl})$ and $\mathrm{AB}(5 \mathrm{mg} / \mathrm{L}$ and $0.10 \mathrm{M} \mathrm{NaCl})$. The absorbance values were recorded at the $\lambda_{\max }$ for each dye.

all other parameters were kept constant. The adsorption capacity is expressed per unit of mass and, seeing the fact

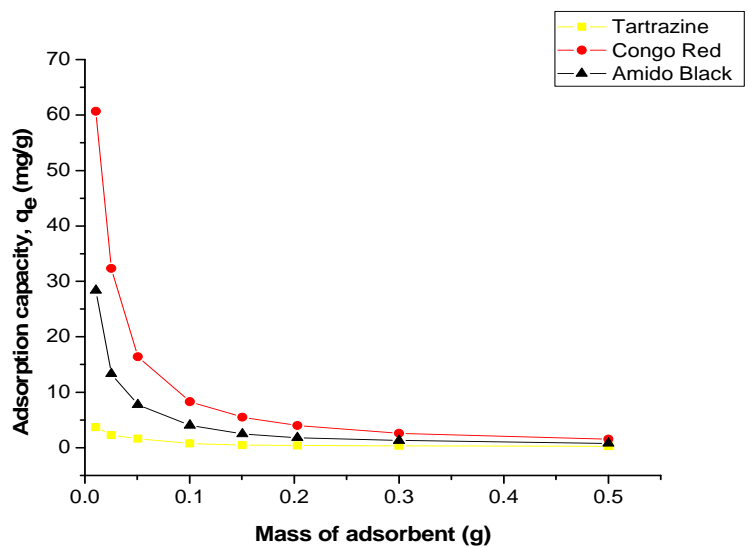

Figure 9. Influence of mass of adsorbent on the adsorption capacity of TAR $(8.34 \mathrm{mg} / \mathrm{L}$ in $0.10 \mathrm{M} \mathrm{NaCl}), \mathrm{CR}(8.34$ $\mathrm{mg} / \mathrm{L}$ in $0.10 \mathrm{M} \mathrm{NaCl})$ and $\mathrm{AB}(5 \mathrm{mg} / \mathrm{L}$ in $0.10 \mathrm{M} \mathrm{NaCl})$. The absorbance values were recorded at the $\lambda_{\max }$ for each dye.

that there is an increase in the mass of sorbent applied to each sample, which contains the same initial concentration of the three dyes, the adsorption capacity decreases with the rise of sorbent dose.

Particle size of chitosan beads was varied. The results showed that the adsorption capacity was not significantly influenced by this parameter (data not presented here).

\subsection{Adsorption Isotherm Studies}

Table 8 lists the calculated results (adsorption constants and correlation coefficients) for the adsorption processes. The main observation is that the best correlation for TAR and $A B$ is to the Freundlich adsorption model $(\mathrm{R}>0.97)$, which involves the presence of multilayers of adsorption on a heterogeneous surface of the sorbent and a possibly reversible adsorption. In the case of CR the correlation is also good, but the Freundlich model of adsorption is not the most appropriate to describe the adsorption of $\mathrm{CR}$ onto chitosan beads (Figure 5).

For CR, the most fitted adsorption mechanism proved to be the Elovich model ((Figure 6), $R=0.9962)$, which also describes a multilayer adsorption mechanism, with exponential increasing in the number of adsorption sites. The Elovich equation model is also described by chemisorptions and due to the high correlation of results obtained for CR, it can be suggested that CR bonds through a coordinate covalent bond to the molecule of chitosan.

The Temkin adsorption model gives clear indications regarding the heat transfer in the process of adsorption. For the two dyes, TAR and AB (Figure 7(a)), the Temkin equation correlated well with the results, as for CR, the correlation was poorer (as can be seen in Table 8), but the values of $\Delta Q$ for all three dyes were positive, describing the adsorption process of TAR, CR and $\mathrm{AB}$ onto chitosan as exothermic. 
Table 8. Experimental isotherm constants and correlation coefficients.

\begin{tabular}{|c|c|c|c|}
\hline Constant & TAR & $\mathrm{CR}$ & $\mathrm{AB}$ \\
\hline \multicolumn{4}{|l|}{ Freundlich model } \\
\hline$n$ & 0.9957 & 0.3952 & 0.8222 \\
\hline$K_{F}\left(\mathrm{mg}^{1-1 / n} \mathrm{~L}^{1 / n} / \mathrm{g}\right)$ & $1.7992 \mathrm{E}-05$ & 4.9994 & 0.0119 \\
\hline$R$ & 0.9756 & 0.9382 & 0.9707 \\
\hline \multicolumn{4}{|l|}{ Temkin model } \\
\hline$K_{0}(\mathrm{~L} / \mathrm{mg})$ & 0.1918 & 2.3869 & 1.4557 \\
\hline$R$ & 0.84 & 0.7978 & 0.9561 \\
\hline \multicolumn{4}{|l|}{ Elovich model } \\
\hline$Q_{m}(\mathrm{mg} / \mathrm{g})$ & & -1.4988 & \\
\hline$K_{E}(\mathrm{~L} / \mathrm{mg})$ & Poor correlation & -0.3606 & $\begin{array}{c}\text { Poor } \\
\text { correlation }\end{array}$ \\
\hline$R$ & & 0.9962 & \\
\hline \multicolumn{4}{|l|}{ Langmuir model } \\
\hline$Q_{m}(\mathrm{mg} / \mathrm{g})$ & & -0.4231 & \\
\hline$B(\mathrm{mg} / \mathrm{g})$ & Poor correlation & 0.3699 & $\begin{array}{c}\text { Poor } \\
\text { correlation }\end{array}$ \\
\hline$R$ & & 0.9579 & \\
\hline
\end{tabular}

The value of the correlation coefficient in the case of $\mathrm{CR}$ also provides information regarding a fitting of the mechanism of adsorption of CR to the Langmuir isotherm model (Figure 7(b)).

\subsection{Kinetics of Adsorption}

The pseudo-first order model yielded in very poor correlation with the values obtained in the kinetic study therefore the data is not presented further. Nevertheless, the pseudo-second order model, turned out to be very well correlated with the experimental data (Table 9). This model is considered to be the most appropriate to describe the entire process of adsorption, not only the initial phase as is the case of the pseudo-first order model. The pseudo-second order kinetic model plot $t / q_{t}=f(t)$ is presented in Figure 10.

\section{Conclusions}

This study presents a predictive methodology for the determination of the concentrations of an organic mixture of dyes (TAR, CR and $\mathrm{AB}$ ) using a spectrophotometric method of detection for the absorbance of the mixture as a whole and univariate and multivariate calibration techniques for the predictive assessment of the concentration of each dye individually within the mixture (PLSR).

Owing to multiple interferences the univariate calibration presents significant errors mostly in the case of TAR, which has the maximum spectral overlapping among the three dyes. $\mathrm{AB}$ has a lower level of spectral overlapping and, thus, the concentration predictions in the case of $\mathrm{AB}$
Table 9. Constants and correlation coefficients of the pseudo-second kinetic model for all three dyes.

\begin{tabular}{ccc}
\hline Dye & $k_{2}(\mathrm{~g} /(\mathrm{mg} \cdot \mathrm{min}))$ & $R^{2}$ \\
\hline $\mathrm{TAR}$ & 0.1405 & 0.9946 \\
$\mathrm{CR}$ & 0.1508 & 0.9997 \\
$\mathrm{AB}$ & 0.949 & 0.9912 \\
\hline
\end{tabular}

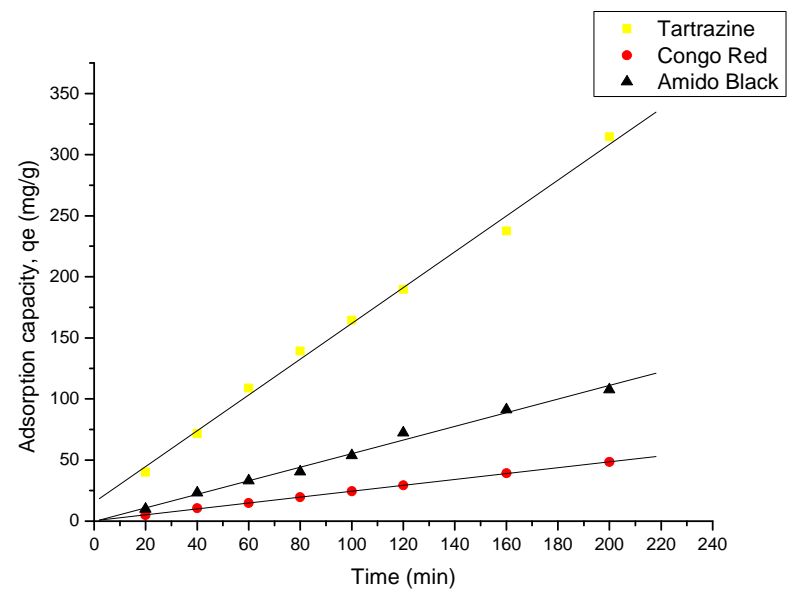

Figure 10. Pseudo-second order plot for the adsorption of TAR (8.34 mg/L in $0.10 \mathrm{M} \mathrm{NaCl}), \mathrm{CR}(8.34 \mathrm{mg} / \mathrm{L}$ in $0.10 \mathrm{M}$ $\mathrm{NaCl})$ and $\mathrm{AB}(5 \mathrm{mg} / \mathrm{L}$ in $0.10 \mathrm{M} \mathrm{NaCl})$ onto chitosan beads. The absorbance values were recorded at the $\lambda_{\max }$ for each dye.

are more accurate. The multivariate calibration shows considerable increase of the accuracy of prediction, due to the fact that interference signals are diminished, by monitoring and using the values of absorption at numerous wavelengths.

The proposed method has proved to be simple, time and cost-efficient for the quantification of three comercial azo dyes in water, using UV-Vis spectrophotometry and PLSR calibration. This method is accurate, reliable and could be used successfully in determining the concentration of dyes in real mixtures from wastewater samples.

The proposed method was applied successfully for the prediction of dye concentrations in mixtures resulting from adsorption processes onto chitosan beads. The adsorption method was optimized to $p \mathrm{H}$, sorbent dose and particle size of chitosan beads, the most suitable $p \mathrm{H}$ being 6.0. Isotherm studies were also performed, concluding that the most suitable model for the adsorption of TAR and AB, onto chitosan beads, is the Freundlich model of adsorption, as for $\mathrm{CR}$, the Elovich isotherm model is more fitted. The adsorption of all three dyes onto chitosan beads is exothermic, due to the value of $\Delta Q$ obtained from the Temkin isotherm model. The kinetic model most appropriate and best correlated to the adsorption 
of all three dyes is the pseudo-second order kinetics model, meaning that the adsorption of all three dyes takes place the entire time during which the dye is in contact with the chitosan beads.

\section{Acknowledgements}

M. M. acknowledges the financial support from strategic grant POSDRU/89/1.5/S/63663, Project “Transnational network of integrated management for postdoctoral research in the field of Science Communication. Institutional construction (post-doctoral school) and fellowship program (CommScie)" financed under the Sectoral Operational Programme Human Resources Development 2007-2013.

\section{REFERENCES}

[1] C. K. Yoo, Y. H. Bang, I.-B. Lee, P. A. Vanrolleghem and C. Rosén, "Application of Fuzzy Partial Least Squares (FPLS) Modeling Nonlinear Biological Processes," Korean Journal of Chemical Engineering, Vol. 21, No. 6, 2004, pp. 1087-1097. doi:10.1007/BF02719479

[2] R. Konduru and T. Viraraghavan, "Dye Removal Using Low Cost Adsorbents," Water Science and Technology, Vol. 36, No. 2-3, 1997, pp. 189-196.

[3] E. Dinç, A. H. Aktaş, D. Baleanu and Ö. Üstündağ, "Simultaneous Determination of Tartrazine and Allura Red in Commercial Preparation by Chemometric HPLC Method," Journal of Food and Drug Analysis, Vol. 14, No. 3, 2006, pp. 284-291.

[4] M. K. Purkait, A. Maiti, S. DasGupta and S. De, "Removal of Congo Red Using Activated Carbon and Its Regeneration," Journal of Hazardous Materials, Vol. 145, No. 1, 2007, pp. 287-295. doi:10.1016/j.jhazmat.2006.11.021

[5] F. A. Pavan, S. L. P. Dias, E. C. Lima and E. V. Benvenutti, "Removal of Congo Red from Aqueous Solution by Anilinepropylsilica Xerogel," Dyes and Pigments, Vol. 76, No. 1, 2008, pp. 64-69. doi:10.1016/j.dyepig.2006.08.027

[6] A. Sayal, V. K. Bulasaram and S. Barman, "A Study on Synthesis of Zeolite and Removal of Amido Black Dye by Adsorption with Zeolite," Chemical and Process Engineering Research, Vol. 2, 2012, pp. 54-64.

[7] S. D. Lambert, N. J. D. Graham, C. J. Sollars and G. D. Fowler, "Evaluation of Inorganic Adsorbents for the Removal of Problematic Textile Dyes and Pesticides," Water Science and Technology, Vol. 36, No. 2-3, 1997, pp. 173-180. doi:10.1016/S0273-1223(97)00385-5

[8] T. K. Saha, N. C. Bhoumik, S. Karmaker, M. G. Ahmed, H. Ichikawa and Y. Fukumori, "Adsorption of Methyl Orange onto Chitosan from Aqueous Solution," Journal of Water Resource and Protection, Vol. 2, No. 10, 2010, pp. 898-906. doi:10.4236/jwarp.2010.210107

[9] C. O’Neill, F. Hawkes, D. Hawkes, N. Lourenço, H. Pinheiro and W. Delée, "Colour in Textile Effluents-Sources, Measurement, Discharge Consents and Simulation: A Re- view," Journal of Chemical Technology and Biotechnology, Vol. 74, No. 11, 1999, pp. 1009-1018.

[10] S. Şahin, C. Demir and Ş. Güçer, "Simultaneous UV-vis Spectrophotometric Determination of Disperse Dyes in Textile Wastewater by Partial Least Squares and Principal Component Regression," Dyes and Pigments, Vol. 73, No. 3, 2006, pp. 368-376. doi:10.1016/j.dyepig.2006.01.045

[11] P. Peralta-Zamora, A. Kunz, N. Nagata and R. J. Poppi, "Spectrophotometric Determination of Organic Dye Mixtures by Using Multivariate Calibration," Talanta, Vol. 47, No. 1, 1998, pp. 77-84. doi:10.1016/S0039-9140(98)00073-3

[12] O. Doka, D. Bicanic, Z. Ajtony and R. Koehorst, "Determination of Sunset Yellow in Multi-Vitamin Tablets by Photoacoustic Spectroscopy and a Comparison with Alternative Methods," Food Additives and Contaminants, Vol. 22, No. 6, 2005, pp. 507-507.

[13] S. Altinöz and S. Toptan, "Determination of Tartrazine and Ponceau-4R in Various Food Samples by Vierordt's Method and Ratio Spectra First-Order Derivative UV Spectrophotometry," Journal of Food Composition and Analysis, Vol. 15, No. 6, 2002, pp. 667-683. doi:10.1006/jfca.2002.1072

[14] J. J. Nevado, C. G. Cabanillas and A. M. Salcedo, "Simultaneous Spectrophotometric Determination of Three Food Dyes by Using the First Derivative of Ratio Spectra," Talanta, Vol. 42, 1995, pp. 2043-2045. doi:10.1016/0039-9140(95)01695-3

[15] D. M. Haaland and E. V. Thomas, "Partial Least-Squares Methods for Spectral Analyses. 1. Relation to Other Quantitative Calibration Methods and the Extraction of Qualitative Information," Analytical Chemistry, Vol. 60, No. 11, 1998, pp. 1193-1202. doi:10.1021/ac00162a020

[16] J. L. López-de-Alba, L. López-Martínez, V. Cerdá and L. M. De-León-Rodríguez, "Simultaneous Determination of Tartrazine, Sunset Yellow and Allura Red in Commercial Soft Drinks by Multivariate Spectral Analysis," Quimica Analitica, Vol. 20, No. 2, 2001, pp. 63-72.

[17] P. Geladi, "Chemometrics in Spectroscopy. Part 1. Classical Chemometrics," Spectrochimica Acta Part B-Atomic Spectroscopy, Vol. 58, No. 5, 2003, pp. 767-782. doi:10.1016/S0584-8547(03)00037-5

[18] B. Hemmateenejad, M. A. Safarpour and A. M. Mehranpour, "Net Analyte Signal-Artificial Neural Network (NASANN) Model for Efficient Nonlinear Multivariate Calibration," Analytica Chimica Acta, Vol. 535, No. 1, 2005, pp. 275-285.

[19] F. Bosch-Reig and P. Campins-Falcó, "H-Point Standard Addition Method Part 1. Fundamentals and Application to Analytical Spectroscopy," Analyst, Vol. 113, 1988, pp. 1011-1016.

[20] M. Perez-Urquiza and J. L. Beltran, "Determination of Dyes in Foodstuffs by Capillary Zone Electrophoresis," Journal of Chromatography A, Vol. 898, No. 2, 2000, pp. 271-275. doi:10.1016/S0021-9673(00)00841-4

[21] P. L. López-de-Alba, L. López-Martínez and L. M. DeLeón-Rodríguez, "Simultaneous Determination of Synthetic Dyes Tartrazine, Allura Red and Sunset Yellow by 
Differential Pulse Polarography and Partial Least Squares. A Multivariate Calibration Method," Electroanalysis, Vol. 14, No. 3, 2002, pp. 197-205. doi:10.1002/1521-4109(200202)14:3<197::AID-ELAN19 7>3.0.CO;2-N

[22] S. Y. Al-Degs, H. A. El-Sheikh, M. A. Al-Ghouti and M. S. Sunjuk, "Determination of Commercial Colorants in Different Water Bodies Using Partial Least Squares Regression (PLS): A Chemometric Study," Jordan Journal of Chemistry, Vol. 3, No. 3, 2008, pp. 321-336.

[23] Y. Bingchao, R. Huang and Q. Lui, "Adsorption of Amido Black 10B onto Cross-Linked Chitosan," Research Journal of Chemistry and Environment, Vol. 16, No. 3, 2012, pp. 110-115.

[24] S. Chatterjee, W. M. Min and H. W. Seung, "Adsorption of Congo Red by Chitosan Hydrogel Beads Impregnated with Carbon Nanotubes," Bioresource Technology, Vol. 101, No. 6, 2010, pp. 1800-1806. doi:10.1016/j.biortech.2009.10.051

[25] W. S. W. Ngah, F. M. A. Noorul and A. K. M. H. Megat, "Preparation, Characterization, and Environmental Application of Crosslinked Chitosan-Coated Bentonite for Tartrazine Adsorption from Aqueous Solutions," Water Air and Soil Pollution, Vol. 206, No. 1-4, 2010, pp. 225-236.

[26] I. Langmuir, "The Constitution and Fundamental Properties of Solids and Liquids," Journal of the American Chemical Society, Vol. 38, No. 11, 1916, pp. 2221-2295. doi:10.1016/S0016-0032(17)90088-2

[27] K. Vijayaraghavan, T. V. N. Padmesh, K. Palanivelu and M. Velan, "Biosorption of Nickel (II) Ions onto Sargassum Wightii: Application of Two-Parameter and Three Parameter Isotherm Models," Journal of Hazardous Materials, Vol. B133, No. 1-3, 2006, pp. 304-308.

[28] S. Kundu and A. K. Gupta, "Arsenic Adsorption onto Iron Oxide-Coated Cement (IOCC): Regression Analysis of Equilibrium Data with Several Isotherm Models and Their Optimization," Chemical Engineering Journal, Vol. 122, 2006, pp. 93-106.

[29] H. M. F. Freundlich, "Over the Adsorption in Solution," Journal of Physical Chemistry A, Vol. 57, 1906, pp. 385471.

[30] A. W. Adamson and A. P. Gast, "Physical Chemistry of Surfaces," 6th Edition, Wiley-Interscience, New York, 1997.

[31] M. I. Temkin, "Adsorption Equilibrium and the Kinetics of Processes on Nonhomogeneous Surfaces and in the Interaction between Adsorbed Molecules," Zhurnal Fizicheskoi Khimii, Vol. 15, 1941, pp. 296-332.

[32] S. Y. Elovich and O. G. Larinov, "Theory of Adsorption from Solutions of Non Electrolytes on Solid (I) Equation Adsorption from Solutions and the Analysis of Its Simplest Form, (II) Verification of the Equation of Adsorption Isotherm from Solutions," Izvestiya Akademii Nauk. SSSR, Otdelenie Khimicheskikh Nauk, Vol. 2, 1962, pp. 209-216.

[33] E. Bulut, M. Ozacar and I. A. Sengil, "Adsorption of Malachite Green onto Bentonite: Equilibrium and Kinetic Studies and Process Design," Microporous Mesoporous Materials, Vol, 115, No. 3, 2008, pp. 234-246. doi:10.1016/i.micromeso.2008.01.039

[34] I. S. McLintock, "The Elovich Equation in Chemisorption Kinetics," Nature, Vol. 216, No. 5121, 1967, pp. 1204 1205. doi:10.1038/2161204a0

[35] Y. S. Ho and G. Mckay, "The Sorption of Lead (II) Ions on Peat," Water Research, Vol. 33, No. 2, 1999, pp. 578584. doi:10.1016/S0043-1354(98)00207-3

[36] M. S. Chiou and H. Y. Li, “Adsorption Behavior of Reactive Dye in Aqueous Solution on Chemical Cross-Linked Chitosan Beads," Chemosphere, Vol. 50, No. 8, 2003, pp. 1095-1105. doi:10.1016/S0045-6535(02)00636-7

[37] B. Hemmateenejad, A. Abbspour, H. Maghami, R. Miri and M. Panjehshahin, "Partial Least Squares-Based Multivariate Spectral Calibration Method for Simultaneous Determination of Beta-Carboline Derivatives," Analytica Chimica Acta, Vol. 575, No. 2, 2006, pp. 290-299.

[38] A. Abbaspour and M. Najafi, "Simultaneous Determination of $\mathrm{Sb}(\mathrm{III})$ and $\mathrm{Sb}(\mathrm{V})$ by Partial Least Squares Regression," Talanta, Vol. 60, No. 5, 2003, pp. 1079-1084.

[39] A. M. C. Davies and T. Fearn, "Back to Basics: Calibration Statistics," Spectroscopy Europe, Vol. 18, No. 2, 2006, pp. 31-32.

[40] P. López-de-Alba, L. López-Martínez, V. Cerdáa and J. Amador-Hernández, "Simultaneous Determination and Classification of Riboflavin, Thiamine, Nicotinamide and Pyridoxine in Pharmaceutical Formulations, by UV-Visible Spectrophotometry and Multivariate Analysis," Journal of the Brazilian Chemical Society, Vol. 17, No. 4, 2006, pp. 715-722. doi:10.1590/S0103-50532006000400012 